\title{
IMPROVEMENT OF AVALABILITY AND PERFORMANCE FACTOR IN PRESS MACHINE USING LEAN CONCEPTS
}

\author{
Vivekananda $\mathbf{T}^{1}$, S. Appaiah ${ }^{2}$ \\ ${ }^{I} P G$ student, Dept. of IEM, M S Ramaiah Institute of Technology, Bangalore, India \\ ${ }^{2}$ Associate Professor, Dept. of IEM, M S Ramaiah Institute of Technology, Bangalore, India
}

\begin{abstract}
In this demanding environment, commercial enterprises confront the vital situation that it ought to utilize most recent innovations to support their profitability with minimum raw materials. Creators ought to have the capacity to give their stock top quality in an extremely esteem successful way to their clients. To meet their client requests, the associations need to move not just in their outside exercises like showcasing, production network and so forth additionally inside exercises like machine usage, process capacity, machine effectiveness and so forth. The center of this anticipate is on enhancing OEE of bottleneck machine $110 \mathrm{~T}$ press with the assistance of incline systems, for example, SMED. The undertaking plans to minimize levels of six major misfortunes along these lines enhancing the productivity of the machine. The venture was begun sans preparation as no information relating to the misfortunes was accessible. Profitability information and machine use points of interest were gathered for 4 months for estimation of beginning OEE and Bottleneck Press. The underlying availability and performance of the bottleneck press was observed to be $55.23 \%$ and $82.79 \%$ respectively. With the backing of creation division the elements in charge of low OEE was recognized. Levels of six major misfortunes were investigated and orderly approach was taken after to expand the effectiveness. Significant misfortunes which are in charge of low OEE is high changeover and were enhanced with the assistance of incline systems like SMED, 5S, TPM and so forth.
\end{abstract}

Keywords-OEE-Overall equipment efficiency, SMED-Single minute exchange of die, Press machine. ****

\section{INTRODUCTION}

The Overall Equipment Effectiveness (OEE), or Lean Manufacturing is presently the key order in a large portion of the fruitful processing plants and assembling plants. The productivity and viability of machines assumes a basic part in deciding the execution of any organization. The causes that influence efficiency of machine like breakdowns, minor stoppages, and decreased velocities. This must be checked and controlled to accomplish most extreme advantages. Industry which has well ability to deal with all offices can make due in this driving assembling market. Raffaele Iannone et.al. (2013) ${ }^{[1]}$ clarifies OEE as a surely understood approach to gauge adequacy and is the foundation of procedures for quality change. Berna Ulutas ( 2011) ${ }^{[2]}$ clarifies in his diaries about the SMED strategy as one of the incline generation strategies for decreasing waste in assembling process. The expression "single moment" stands for "single-digit moment" which implies that all changeovers and new businesses ought to take under 10 minutes, SMED was initially created to enhance kick the bucket press and machine instrument setups, however also its standards apply to changeovers in a wide range of procedures. E.Sivaselvam, et.al ${ }^{[3]}$ in his paper expects to distinguish un profitability time misfortunes inside the framework and these time misfortunes influence accessibility, execution and quality. It is found that collaboration is essential in taking care of the issues happened in machines. Ascertaining the OEE likewise give the organization where they are and where is the shortcoming point and how to move forward. Tushar $\mathrm{N}$.
Desai, et.al. (2008) ${ }^{[4]}$ presents an instructional exercise overview on how DMAIC philosophy in an industry gives a structure to distinguish, measure and wipe out wellsprings of variety in an operational procedure. The apparatuses and methods that can be utilized amid each period of DMAIC and their favorable circumstances have been depicted quickly with a delineated contextual analysis of expansive size assembling industries.

\section{PROBLEM STATEMENT}

The WIP in the CMD shop is huge and thus has to be identify which is the bottleneck machine and OEE improvement process has carried out to improve the productivity of that machine.

\section{METHODS AND METHODOLOGY}

$>$ Identification of the bottleneck machine.

$>$ Detailed time study contributing for bottleneck.

$>$ Pareto Analysis.

$>$ Selection of significant ranges to center.

$>$ Why-Why examination for real ranges.

$>$ Developing the new model.

$>$ Planning and usage.

$>$ Results and approval.

\subsection{Identification of Bottleneck Machine}

The procedure stream information has been gathered from the Production Planning and Control bureau of CMD shop little squeeze line generation plan information have gathered 


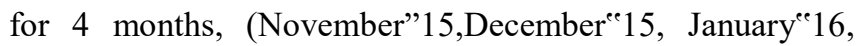
Februarye 16) from that, bottleneck machine has been investigated. The investigation demonstrates that $110 \mathrm{~T}$ press machine was the bottleneck in the CMD line. The points of interest have been shown in table 1 .

Table 1. Average of 4 month production stroke \& its percentage

\begin{tabular}{|c|c|c|c|}
\hline & \multicolumn{2}{|c|}{ Average of 4 month } & \\
\hline Press list & \multicolumn{2}{|c|}{ Production Strokes Details } & \\
\hline & Plan & Actual & Percentage \\
\hline $45 \mathrm{~T}-2$ & 102438 & 92194 & $90 \%$ \\
\hline $63 \mathrm{~T}-4$ & 139742 & 131357 & $94 \%$ \\
\hline $160 \mathrm{~T}-2$ & 156454 & 139244 & $89 \%$ \\
\hline $100 \mathrm{~T}-1$ & 150275 & 136750 & $91 \%$ \\
\hline $160 \mathrm{~T}-1$ & 184773 & 164447 & $89 \%$ \\
\hline $110 \mathrm{~T}$ & 123929 & 86750 & $70 \%$ \\
\hline
\end{tabular}

The points of interest specified in table 1 demonstrates that creation subtle elements (Plan/Actual) for the CMD little squeeze line. In view of the profitability investigation every press singular strokes has been gathered physically and recognized that $110 \mathrm{~T}$ Press machine is the bottleneck.

The $110 \mathrm{~T}$ kind of squeezing machine utilized as a part of organization is mechanical press which is utilized with the assistance of pneumatic and hydraulic.

\subsection{Time Study on Bottleneck Press}

The venture was begun from the scratch as no information relating to the misfortunes was accessible. From the information examination on efficiency $110 \mathrm{~T}$ was recognized as the bottleneck press machine for stamped parts. it can't accomplish generation according to necessity. For finding the reasons of bottleneck, information gathering configuration was set up for machine usage and Losses recognizable proof. Based on the time study, tool change over time is taking more time.

\subsection{Reasons for High Changeover Process}

This changeover procedure flowchart gives the points of interest of movement from when the real generation with past stamping instrument is done to crisp creation from new stamping apparatus to be prepared. This setting incorporates the stacking and emptying of sheet material and stamping apparatus to finish a full setting time. At present existing changeover time is 88.02 mins.

\subsection{Pareto Analysis}



Based on the analysis tool setting time is taking more time. So the entire project is meant to reduce the tool setting time.

\subsection{Selection of significant ranges to center}

\section{Changeover Time}

a. Waiting time is more for next press tool

b. Waiting for tool setters

c. Tools searching

\section{SMED CONCEPT}

Single Minute Exchange Of Dies (SMED) is one of the essential incline devices which require submitted exertion. This exertion fizzles once in a while on the grounds that associations fall into the longing to surge with an almost no or no forthright arranging. With constrained time and assets, the exertion is destined for disappointment. So it is especially important to execute SMED deliberately (Berna Ulutas, 2011). For this action a backing requires from the distance of industry incorporates Design, Quality and Maintenance. With this methodology it is effectively conceivable to lessen changeover time in $110 \mathrm{~T}$ Press. A Seven stage approach is made from the inputs of literary works, books and web articles. SMED has seven steps explained below.

\subsection{Observe the Current Practices of Tool Change}

\section{Activity}

The perception of current practices of hardware change movement was noted down for 15 times of changeover. The base time of changeover is taken as $76 \mathrm{~min}$, most extreme time of changeover is taken as $98 \mathrm{~min}$ and the normal time of changeover is taken as $86.8 \mathrm{~min}$.

\subsection{Study the Elemental Activities of Die}

\section{Changeover.}

In $110 \mathrm{~T}$ Press every one of the exercises identified with change after some time conveys inside, it causes more down time and it prompts generations misfortune. Point of this progression is to distinguish the where precisely process is 
slacking. The present practices saw from the subtle element time study investigation and video study examination. In $110 \mathrm{~T}$ Press every one of the exercises identified with change after some time conveys inside, it causes more down time and it prompts generation misfortune.

\subsection{Separate the Internal \& External Activites}

Overall changeover time exercises were partitioned into outside and inside classifications. That is to say, there is a plausibility to bring the press creation time progressively when the exercises have been isolated.

\subsection{Externalizing Internal Activities}

In this progression it is obviously sorted that exercises which should have been changing over to outer had been changed over. The timings of the individual setup is condensed. The consequence of this progression, the apparatus inward changeover time is lessened from 88.08 $\min$ to $33.6 \mathrm{~min}$.

\subsection{Improve Internal Setup Activities}

After execution of arrangements there are some figures that enhanced such a large number of exercises and some variables has been disposed of. Before usage of arrangements the inner changeover time was $33.6 \mathrm{~min}$, in the wake of building up the arrangements the inward changeover time has boiled down to $11.1 \mathrm{~min}$.

\subsection{Improve External Setup Activities}

Before implementing of solutions the external changeover time was $54.48 \mathrm{~min}$, after developing the solutions it has come down to $18.73 \mathrm{~min}$.

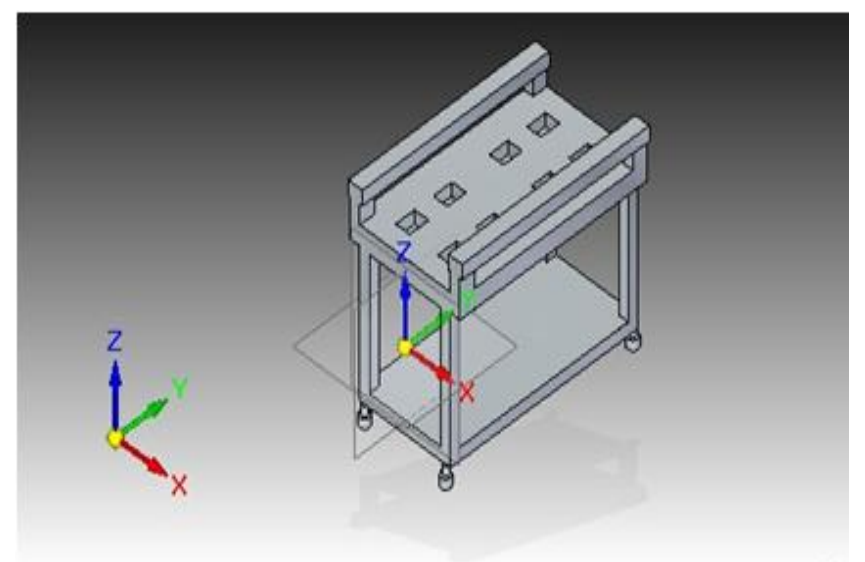

Fig 1 shows the 3-d image of Movable Die Trolley

\section{RESULTS}

Before implementation, internal setup time is $33.6 \mathrm{~min}$. After solutions implemented, the eliminated time in internal setup is $22.48 \mathrm{~min}$. External setup time come down from $54.48 \mathrm{~min}$ to $18.73 \mathrm{~min}$. Eliminated time was $35.75 \mathrm{~min}$.

\section{Cost Savings Calculation on Component}

$>$ A component arrives $=10$ times per a month.

$>$ Each hour production=300components*4Rs /component.

$>$ Average setup per day $=2$ changeovers.

$>$ Before SMED implementation $=2 * 88.08=\sim 3$ hrs(wasted).

$>$ After SMED implementation=88.08-29.83 $=58.25 \mathrm{mins} * 2$ $=\sim 2 \mathrm{hrs}($ saved $)$.

$>$ One hour Press Cost $=350 / \mathrm{hr}$

$$
\begin{aligned}
& =2 * 350 \\
& =700 \text { Rs per day }
\end{aligned}
$$

$>$ For one month $=700 * 10$ times

$$
=7,000 \text { Rs per month }
$$

$>$ For one year $=7000 * 12$ months

$$
=84,000 \text { Rs per year }
$$

\section{Capacity Improvement after SMED}

After the execution of SMED the profitability of the $110 \mathrm{~T}$ press machines had been expanded. The capacity had been expanded from 1500 parts for each movement to 2100 segments in one shift. This enhances the result and turnover of the organization. SMED usage diminished the changeover time and the proficiency of the works.

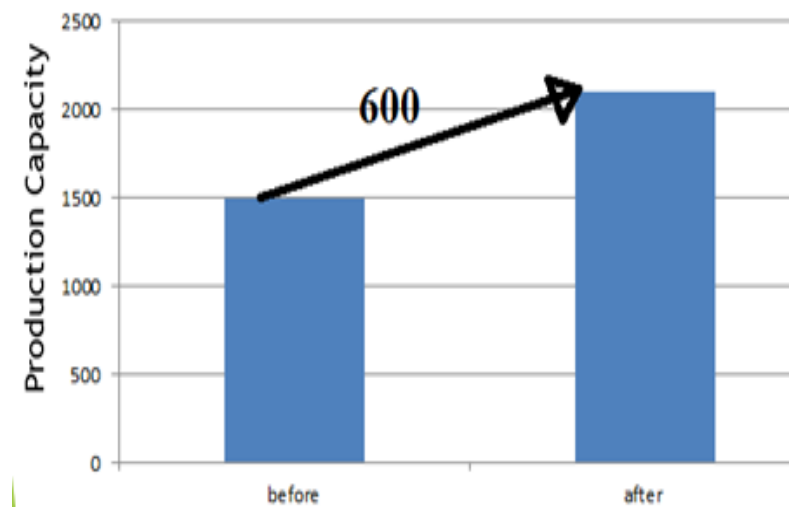

Validation of the improvement of Availability and Performance

> Shift Length=144 hrs=8640 mins

> Short breaks=18 breaks @ 15min each=270 mins

$>$ Meal breaks=18 breaks @ 30mins each=540 mins

$>$ Ideal run rate $=5$ PPM( Piece Per Minute)

$>$ Down time $=2932$ mins

$>$ Total piece $=21600$

$>$ Reject piece $=180$

$>$ Production time $=$ shift length - breaks $=7830 \mathrm{mins}$

$>$ Operating time $=$ Planned production time-DT $=4898$ mins

$>$ Good piece $=$ Total piece-reject piece $=21420$ pieces

$>$ Availability $=$ operating time/PPT $* 100=62.55 \%$

$>$ Performance $=($ Total piece/operating time $) /$ ideal run rate $^{* 100}=\mathbf{8 8 . 2 0 \%}$

$>\quad$ Quality $=(\operatorname{good}$ piece $/$ total pieces $) * 100=99.17 \%$

$>$ OEE $=($ Avalability*Performance*Quality $) * 100$

$>\mathbf{5 4 . 7 1 \%}$ 


\section{CONCLUSION}

$>$ Implementation of incline instruments in a press shop makes the machining procedure more adaptable to meet the changing requests of the clients.

$>$ SMED execution enhances the adaptability in assembling by accomplishing more noteworthy item assortment inside the accessible assets and supporting group sizes.

$>$ Proposed SMED strategy Movable Die trolley and Standardization of clipping would decrease the accessibility misfortunes and straightforwardness set-up procedure.

> After execution of SMED the availability and performance has been increased to $62.55 \%$ and $88.20 \%$.

\section{REFERENCES}

[1] Raffaele Iannone et.al. (2013). Managining OEE to Optimize Factory Performance. [online].

[2] Berna Ulutas (2011). An application of SMED Methodology. Turkey, Eskisher 26480.

[3] E.Sivaselvam, et.al. (n.d.) Improvement of Overall Equipment Effectiveness in a Plastic Injection Moulding Industry. IOSR Journal of Mechanical and Civil Engineering, 12-16.

[4] Tushar N. Desai, et.al. (Oct-2008). Six-sigma-A new direction to quality and Productivity Management. J. Clerk Maxwell, A Treatise on Electricity and Magnetism, 3rd ed., vol. 2. Oxford: Clarendon, 1892, pp.68-73.

[5] Huang, et.al. (2006). Performance Measurement using Overall equipment effectiveness (OEE):Literature review and Practical application discussion. International Journal of Production Research, IJPR-0559 (R1)

[6] Robert C.Hansen (Jan-2001 ). Overall Equipment Effectiveness. Industrial Press Inc - Technology \& Engineering, 278. 